\title{
Intraoperative MRI versus 5-ALA in high-grade glioma resection: a network meta-analysis
}

\author{
Danielle Golub, BA, ${ }^{1}$ Jonathan Hyde, BS, ${ }^{1}$ Siddhant Dogra, BS, ${ }^{2}$ Joseph Nicholson, MLIS, MPH, ${ }^{3}$ \\ Katherine A. Kirkwood, MS, ${ }^{4}$ Paulomi Gohel, BS, ${ }^{1}$ Stephen Loftus, PhD, ${ }^{5}$ and \\ Theodore H. Schwartz, MD 6
}

\begin{abstract}
Departments of ${ }^{1}$ Neurosurgery and ${ }^{2}$ Radiology, New York University School of Medicine, New York, New York; ${ }^{3} \mathrm{NYU}$ Health Sciences Library, New York University School of Medicine, New York, New York; ${ }^{4}$ Department of Population Health Science and Policy, Icahn School of Medicine at Mount Sinai, New York, New York; ${ }^{6}$ Departments of Neurosurgery, Otolaryngology, and Neuroscience, Weill Cornell Medicine, NewYork-Presbyterian Hospital, New York, New York; and ${ }^{5}$ Department of Science, Technology, Engineering and Math, Sweet Briar College, Sweet Briar, Virginia
\end{abstract}

\begin{abstract}
OBJECTIVE High-grade gliomas (HGGs) continue to carry poor prognoses, and patient outcomes depend heavily on the extent of resection (EOR). The utility of conventional image-guided surgery is limited by intraoperative brain shift. More recent techniques to maximize EOR, including intraoperative imaging and the use of fluorescent dyes, combat these limitations. However, the relative efficacy of these two techniques has never been systematically compared. Thus, the authors performed an exhaustive systematic review in conjunction with quantitative network meta-analyses to evaluate the comparative effectiveness of 5-aminolevulinic acid (5-ALA) and intraoperative MRI (IMRI) in optimizing EOR in HGG. They secondarily analyzed associated progression-free and overall survival and performed subgroup analyses by level of evidence.
\end{abstract}

METHODS PubMed, Embase, Cochrane Central, and Web of Science were searched for studies evaluating conventional neuronavigation, IMRI, and 5-ALA in HGG resection. The primary study endpoint was the proportion of patients attaining gross-total resection (GTR), defined as 100\% elimination of contrast-enhancing lesion on postoperative MRI. Secondary endpoints included overall and progression-free survival and subgroup analyses for level of evidence. Comparative efficacy analysis of IMRI and 5-ALA was performed using Bayesian network meta-analysis models.

RESULTS This analysis included 11 studies. In a classic meta-analysis, both IMRI (OR 4.99, 95\% Cl 2.65-9.39, p < 0.001 ) and 5-ALA (OR 2.866, 95\% Cl 2.127-3.863, $p<0.001$ ) were superior to conventional navigation in achieving GTR. Bayesian network analysis was employed to indirectly compare IMRI to 5-ALA, and no significant difference in GTR was found between the two (OR 1.9 favoring IMRI, 95\% $\mathrm{Cl} 0.905-3.989, p=0.090)$. A handful of studies additionally suggested that the use of either IMRI ( 2 and 4 studies, respectively) or 5 -ALA ( 2 and 2 studies, respectively) improves progression-free and overall survival.

CONCLUSIONS IMRI and 5-ALA are individually superior to conventional neuronavigation for achieving GTR of HGG. Between IMRI and 5-ALA, neither method is clearly more effective. Future studies evaluating the comparative cost and surgical time associated with IMRI and 5-ALA will better inform any cost-benefit analysis.

https://thejns.org/doi/abs/10.3171/2019.12.JNS191203

KEYWORDS intraoperative MRI; 5-aminolevulinic acid; glioma; glioblastoma; neuronavigation; oncology; surgical technique

$\mathrm{G}$ LIOMAS represent the largest group of primary central nervous system (CNS) tumors, making up nearly $80 \%$ of malignant CNS tumors. ${ }^{41}$ Despite decades of research, prognosis for high-grade glioma (HGG) remains poor. ${ }^{4}$ Extent of resection (EOR) is a key prognostic factor in glioma and has been positively asso- ciated with overall survival, quality of life, delay in malignant transformation, seizure-free rate, and duration of functional independence. ${ }^{37,49,73}$ Preoperative surgical planning to maximize EOR with stereotactic image-guided neuronavigation has become nearly routine but is inherently limited by being based on preoperative imaging alone.

ABBREVIATIONS 5-ALA = 5-aminolevulinic acid; EOR = extent of resection; GTR = gross-total resection; HGG = high-grade glioma; IMRI = intraoperative MRI; LGG = low-grade glioma; QALY = quality-adjusted life year; RCT = randomized controlled trial; SDM = standard difference in means.

SUBMITTED April 29, 2019. ACCEPTED December 16, 2019.

INCLUDE WHEN CITING Published online February 21, 2020; DOI: 10.3171/2019.12.JNS191203. 
Brain shift during surgery because of gravity, edema, fluid shifts, and other physiological changes associated with surgery makes preoperative image guidance unreliable as surgery progresses and limits the safe maximal resectability of invasive lesions. ${ }^{23}$

Several innovations have recently emerged to compensate for the limitations of neuronavigation, such as fluorescent tumor markers. ${ }^{61}$ 5-aminolevulinic acid (5-ALA)-a naturally occurring heme precursor capable of producing fluorescent porphyrins in malignant tissue-is the most widely used marker and carries the highest level of evidence for expanding EOR and prolonging progressionfree survival in glioma patients. ${ }^{60,61,75}$ Additionally, intraoperative imaging modalities such as intraoperative MRI (IMRI), introduced to neurosurgery in 1997, can update source images and spatial information for neuronavigation. ${ }^{66}$ While IMRI is more effective than classic stereotactic navigation in improving EOR, it is expensive, prolongs operating time, and increases the complexity of the operating room..$^{35,53}$

While several studies have compared the use of either 5-ALA or IMRI with stereotactic navigation, quantitative comparison of 5-ALA with IMRI for maximizing EOR remains limited. But this question is important for several reasons. First, if one technology is superior, then the inferior technology may eventually fall out of favor. Second, if the two technologies are similarly efficacious, then institutions with limited resources may opt to invest in the less expensive technology. We performed an exhaustive systematic review in conjunction with quantitative network meta-analyses to evaluate the comparative effectiveness of 5-ALA and IMRI in optimizing EOR in HGG. We secondarily analyzed associated progression-free and overall survival and performed subgroup analyses by level of evidence.

\section{Methods}

\section{Research Protocol and Search Question}

Our review protocol was developed according to the PRISMA statement guidelines (see the PRISMA Checklist) and is registered with PROSPERO (registration no. CRD42018111524). ${ }^{38}$ The search strategy was designed using a PICO (patient, intervention, comparator, outcome)based research question: in adult patients with HGG, what is the comparative effectiveness of conventional stereotactic navigation, 5-ALA, and IMRI for achieving gross-total resection (GTR)? ${ }^{50}$ Both observational and interventional studies were included, but given our intent to perform a quantitative meta-analysis, only those articles describing at least one comparator group were included.

\section{Eligibility Criteria and Primary Outcome}

Preliminary searches revealed a shortage of comparative prospective studies and randomized controlled trials (RCTs) on intraoperative navigational adjuncts. This is consistent with the findings of a recent systematic review on neuronavigation in glioma whose authors were unable to perform a comparative efficacy analysis because of limited data since an eligibility criterion limited studies to RCTs alone. ${ }^{31}$ For a more comprehensive analysis, we included all types of peer-reviewed publications, with both observational and interventional studies meeting the eligibility criteria.

Studies eligible for inclusion met the following criteria: 1) observational or interventional peer-reviewed studies published in the English language between 1997 and 2019; 2) subjects were adults (age 16 or older) with HGG (WHO grades III-IV); 3) GTR of the lesion was intended for all subjects; 4) at least 2 neuronavigational adjuncts were used, including conventional stereotactic navigation, IMRI, or 5-ALA; and 5) the primary outcome of interest was reported, that is, the number or proportion of patients per neuronavigational adjunct who had attained GTR, which was defined as $100 \%$ resection of contrast-enhancing lesion on postoperative MRI. Relevant exclusion criteria were as follows: 1) case reports, case series, and review articles or other article types in which there was no comparator group; 2) the study included spinal or peripheral nerve lesions; 3) the study reported outcomes for additional tumor types (e.g., metastases, low-grade gliomas) that could not be separated from the HGG data; 4) surgery involved stereotactic radiosurgery or laser interstitial thermal therapy; and 5) neuronavigation involved virtual reality.

\section{Search Strategy and Study Selection}

PubMed, Embase, Cochrane Central, and Web of Science were searched for articles by systematically using a defined search strategy with a combination keyword and medical subject heading (MeSH)-based approach adapted for each database (see Appendix). The most recent search was performed on January 25, 2019. The reference lists of all publications were additionally reviewed.

A two-step review of all articles was performed. First, two reviewers independently screened all titles and abstracts for relevance. Second, two independent reviewers assessed the full text of screened articles for eligibility. An additional exclusion criterion for full-text assessment was overlapping data from the same cohort in different studies. All discrepancies were resolved by a third independent reviewer.

\section{Data Collection and Quality Assessment}

Data were independently extracted from the included articles by two reviewers (with disagreements resolved by discussion) and were stored in an electronic database. Data fields included study characteristics (authors, publication year, study design, period of study), neuronavigational intervention, sample size overall and by intervention, patient age, primary outcome as defined above, additional intraoperative navigational adjuncts used, and secondary outcomes including overall survival and progression-free survival.

Study quality and risk of bias were assessed independently for observational and interventional studies. Observational case-control and cohort studies, both retrospective and prospective, were assessed using a modified Newcastle-Ottawa Scale. ${ }^{68}$ RCTs were assessed using the Cochrane Risk of Bias Tool. ${ }^{28}$ Both assessments were performed by two reviewers, with discrepancies resolved by a third independent reviewer. 


\section{Statistical Analysis and Quantitative Data Synthesis}

Neuronavigational interventions were compared using both classic random-effects meta-analysis and Bayesian network meta-analysis for the primary outcome. Analysis of secondary outcomes was limited to classic meta-analysis because of an insufficient number of studies. In both cases, the effect was expressed by an odds ratio and 95\% confidence interval where a $\mathrm{p}$ value $<0.05$ was considered statistically significant, and random-effects models were used throughout to account for interstudy heterogeneity. ${ }^{3}$ The network meta-analysis employed noninformative priors in the generalized linear model using a logit link and assuming a binomial distribution of patients with the outcome. Sensitivity analyses were conducted to ensure robustness by a) treating the study as a fixed effect and b) assuming different priors on the standard deviation of the random effect (study) in the random-effects model. ${ }^{16}$ Higgins $\mathrm{I}^{2}$ tests were used to analyze study heterogeneity. ${ }^{29}$ Publication bias was also graphically assessed using funnel plots. ${ }^{59}$ Comprehensive Meta-Analysis (CMA) software version 3.0 (Biostat Inc.) was used for classic meta-analysis and assessment of publication bias. Bayesian network meta-analysis was performed using SAS 9.4 software (SAS Institute) and the Microsoft Excel-based tool NetMetaXL (Microsoft Corp.; using WinBUGS version 1.4.3, Medical Research Council Biostatistics Unit). ${ }^{5}$

\section{Results}

A total of 4721 articles were identified. After de-duplication and initial screening, 379 full-text studies were assessed for eligibility, resulting in 11 included studies (Fig. 1). Seven studies described the use of IMRI $8,39,40,45$, $55,70,74$ and 6 studies described the use of 5-ALA $6,17,32,40,45,62$ for HGG resection. General study characteristics, primary outcomes, and survival data for studies comparing IMRI to conventional navigation are listed in Table 1, and those for studies comparing 5-ALA to conventional navigation are listed in Table 2.

\section{IMRI Versus Conventional Navigation}

Of the 7 studies describing IMRI, 6 were observational and 1 was an RCT (Table 1). Overall, 236 cases using IMRI were compared to 233 cases using conventional navigation between 2004 and 2014. Rates of GTR with IMRI ranged from $31.4 \%$ to $100 \%$ of patients. Only 1 study evaluated low-field $(<1.5 \mathrm{~T})$ IMRI. ${ }^{55}$ The use of additional navigational adjuncts varied: diffusion tensor imaging (DTI) was used in 3 studies, ${ }^{8,70,74}$ neurophysiological monitoring was definitely used in 1 study $^{40}$ and may have been used in 2 additional studies, ${ }^{45,70}$ blood oxygen leveldependent functional MRI (BOLD fMRI) was used in 1 study, ${ }^{74}$ and intraoperative ultrasound may have been used in 1 study. ${ }^{45}$ Two studies did not comment on the use of additional navigational technologies. ${ }^{39,55}$

All studies reported the number of patients in the IMRI and conventional navigation groups for whom GTR had been achieved. Moderate heterogeneity between trials was observed per the Higgins test $\left(\mathrm{I}^{2}=28.18 \%\right)$, and given the differences inherent to institution and surgeon experience and across study types (retrospective vs prospective), ran-

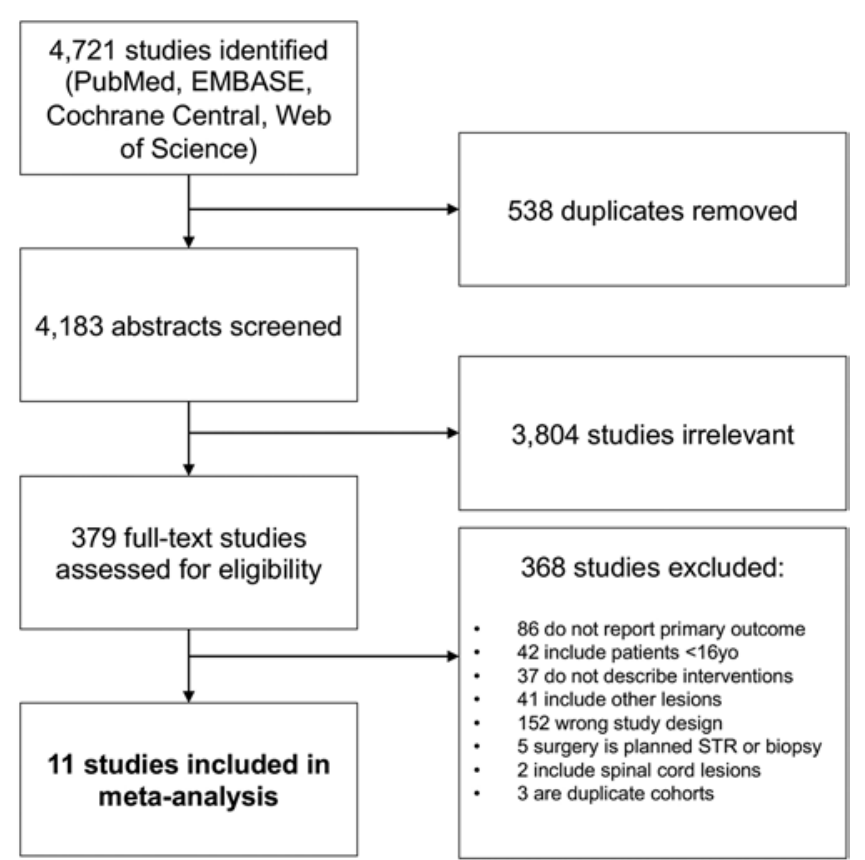

FIG. 1. Flow diagram of search results and assessment of eligibility.

dom-effects models were used. In a classic meta-analysis, IMRI was superior to conventional stereotactic navigation for achieving GTR in adults with HGG (OR 4.99, 95\% CI 2.65-9.39, p < 0.001; Fig. 2A). IMRI, as compared to conventional navigation, also prolonged both progression-free survival (standard difference in means [SDM] 0.656, 95\% CI $0.330-0.983, \mathrm{p}<0.001$; Fig. 2B) and overall survival (SDM 0.491, 95\% CI 0.212-0.771, $\mathrm{p}=0.001$; Fig. 2C).

\section{5-ALA Versus Conventional Navigation}

Six studies described using 5-ALA for HGG resection; 5 were observational and the sixth was an RCT (Table 2). Overall, 487 cases using 5-ALA were compared to 495 cases using conventional stereotactic navigation between 1999 and 2016. Rates of GTR with 5-ALA ranged from $44.7 \%$ to $80 \%$. Across studies, the administration of 5-ALA was consistent (20-mg/kg dose given 2-4 hours before surgery). Regarding additional neuronavigational adjuncts, 2 studies described the use of neurophysiological monitoring, ${ }^{32,40} 1$ study may have used neurophysiological monitoring or intraoperative ultrasound, ${ }^{45}$ and 3 studies were not specific about additional navigational tools. ${ }^{6,17,62}$

In a classic meta-analysis, 5-ALA, as compared to conventional stereotactic navigation, significantly increased the likelihood of achieving GTR (OR 2.866, 95\% CI 2.127-3.863, $\mathrm{p}<0.001$; Fig. 3A). Interstudy heterogeneity among the 5-ALA studies was limited according to the Higgins test $\left(I^{2}=12.56 \%\right)$. Two studies commented on survival outcomes, including the RCT: 5-ALA improved both progression-free survival (SDM 0.495, 95\% CI 0.068-0.922, $\mathrm{p}=0.023$; Fig. 3B) and overall survival (SDM 0.245, 95\% CI 0.010-0.480, p = 0.041; Fig. 3C). 


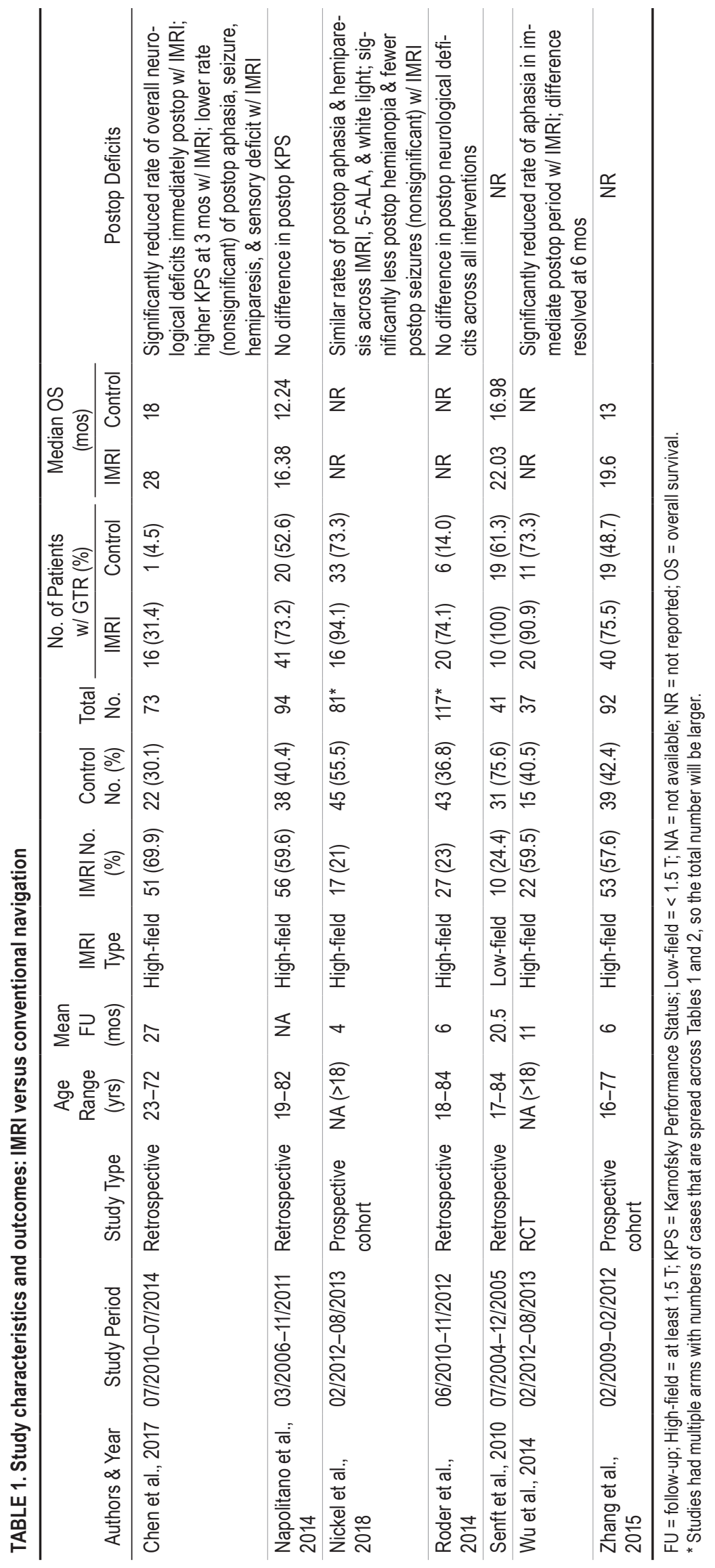




\section{IMRI Versus 5-ALA: Network Meta-Analysis}

Network meta-analysis methods were employed to compare GTR rates between IMRI and 5-ALA, using the assumption that the control group was conventional stereotactic navigation under white light. The results of the Markov chain Monte Carlo (MCMC) network metaanalysis are shown in Fig. 4A, and a network diagram illustrating the strength of the inferred comparisons is shown in Fig. 4B. Between IMRI and 5-ALA, neither intervention was found to be superior at facilitating GTR in HGG surgery (OR 1.9 favoring IMRI, 95\% CI $0.905-$ $3.989, p=0.090$ ), with a trend favoring IMRI. Sensitivity analysis comparing the outcomes of a fixed-effects model was also performed (Supplemental Fig. S1) and confirmed the effect in the same direction, but interstudy heterogeneity supports favoring the outcomes of the random-effects model.

\section{Methodological Quality and Risk of Bias Assessments}

The methodological quality of the included studies was assessed using the Cochrane Risk of Bias Tool for RCTs (Supplemental Table 1) and a modified Newcastle-Ottawa Scale for observational studies (Supplemental Table 2). ${ }^{28,68}$ Among the IMRI studies, the sole RCT, by Wu et al., reported only an interim analysis generating uncertainty in outcome and reporting, and surgeon blinding was not possible throughout the study ${ }^{70}$ Among the 6 observational studies on IMRI, 2 studies left selection of the exposed cohort up to surgeon discretion rather than based on IMRI availability, ${ }^{39,55} 2$ studies either did not report selection of the nonexposed cohort or used historical controls, ${ }^{40,45}$ and 4 studies failed to achieve cohort comparability for lack of reporting outcomes by tumor location, ${ }^{39,40,45,55}$ yielding a mean Newcastle-Ottawa Scale score of 4.8/7. Among the 5-ALA studies, the RCT, by Stummer et al., had similar issues with surgeon blinding and used a per-protocol analysis since several patients were lost to follow-up or had technical issues with the 5-ALA-introducing attrition bias. ${ }^{62}$ Of the 5 observational studies, 4 were cohort studies and 1 was a case-control study; none of the cohort studies described an unbiased process for selection of the nonexposed cohort, ${ }^{17,32,40,45}$ and 2 did not report outcomes by tumor location, ${ }^{40,45}$ yielding a mean Newcastle-Ottawa Scale score of 4.5/7. In the case-control study, by Bruch et al., limited information on case representativeness, control selection, and nonresponse rate was available given the study's abstract format. ${ }^{6}$

Publication bias was also assessed using funnel plots of standard error by log odds ratio for the outcome of GTR rate for IMRI studies (Fig. 5A), 5-ALA studies (Fig. 5B), and the two in combination (Fig. 5C).$^{59}$ Among the IMRI studies, a lack of symmetry in the funnel plot and the presence of studies falling outside the $95 \%$ confidence interval was observed, while among the 5-ALA studies, plot symmetry indicated a lower risk of bias. Among all studies tested in the network meta-analysis, there was some asymmetry of the funnel plot (driven by the IMRI studies), but all studies fell within the confidence interval, suggesting an intermediate level of bias.

Lastly, the IMRI and 5-ALA studies were separately assessed in subgroup analyses by study type to determine

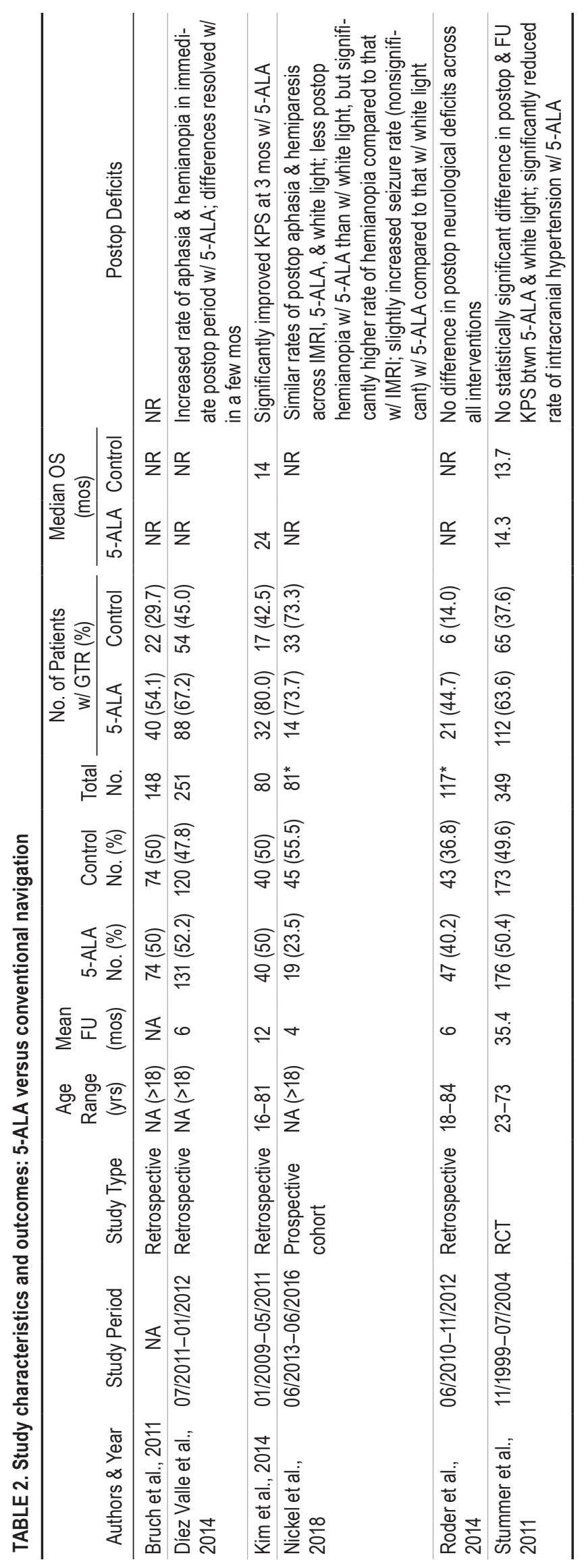




\begin{tabular}{lrrrr} 
Study name & \multicolumn{5}{c}{ Statistics for each study } \\
\cline { 2 - 5 } & $\begin{array}{r}\text { Odds } \\
\text { ratio }\end{array}$ & $\begin{array}{c}\text { Lower } \\
\text { limit }\end{array}$ & \multicolumn{1}{c}{$\begin{array}{c}\text { Upper } \\
\text { limit }\end{array}$} & p-Value \\
Chen 2017 & 9.600 & 1.186 & 77.729 & 0.034 \\
Napolitano 2014 2.460 & 1.032 & 5.866 & 0.042 \\
Nickel 2018 & 5.818 & 0.694 & 48.743 & 0.104 \\
Roder 2014 & 17.619 & 5.209 & 59.594 & 0.000 \\
Senft 2010 & 13.462 & 0.723 & 250.736 & 0.081 \\
Wu 2014 & 3.636 & 0.572 & 23.126 & 0.171 \\
Zhang 2015 & 3.239 & 1.335 & 7.859 & 0.009 \\
& 4.990 & 2.651 & 9.393 & 0.000
\end{tabular}

A

\begin{tabular}{lrrrrr} 
Study name & \multicolumn{5}{c}{ Statistics for each study } \\
\cline { 1 - 4 } & $\begin{array}{c}\text { Std diff } \\
\text { in means }\end{array}$ & $\begin{array}{c}\text { Lower } \\
\text { limit }\end{array}$ & $\begin{array}{c}\text { Upper } \\
\text { limit }\end{array}$ & p-Value \\
Chen 2017 & 0.675 & 0.163 & 1.187 & 0.010 \\
Zhang 2015 & 0.644 & 0.220 & 1.067 & 0.003 \\
& 0.656 & 0.330 & 0.983 & 0.000
\end{tabular}

B

\begin{tabular}{lrrrrr} 
Study name & \multicolumn{4}{c}{ Statistics for each study } \\
\cline { 3 - 5 } & $\begin{array}{c}\text { Std diff } \\
\text { in means }\end{array}$ & $\begin{array}{c}\text { Lower } \\
\text { limit }\end{array}$ & $\begin{array}{c}\text { Upper } \\
\text { limit }\end{array}$ & p-Value \\
Chen 2017 & 0.548 & 0.041 & 1.056 & 0.034 \\
Napolitano 2014 & 0.159 & -0.253 & 0.572 & 0.450 \\
Senft 2010 & 0.678 & -0.050 & 1.405 & 0.068 \\
Zhang 2015 & 0.718 & 0.291 & 1.144 & 0.001 \\
& 0.491 & 0.212 & 0.771 & 0.001
\end{tabular}

C

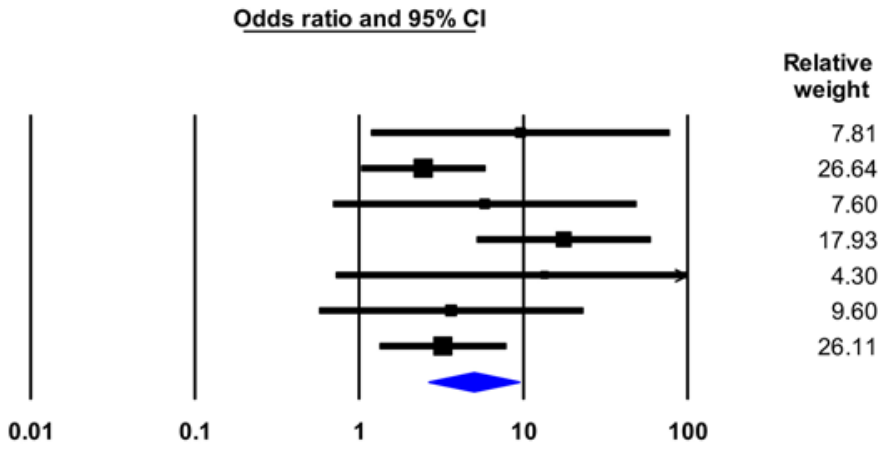

Conventional Navigation
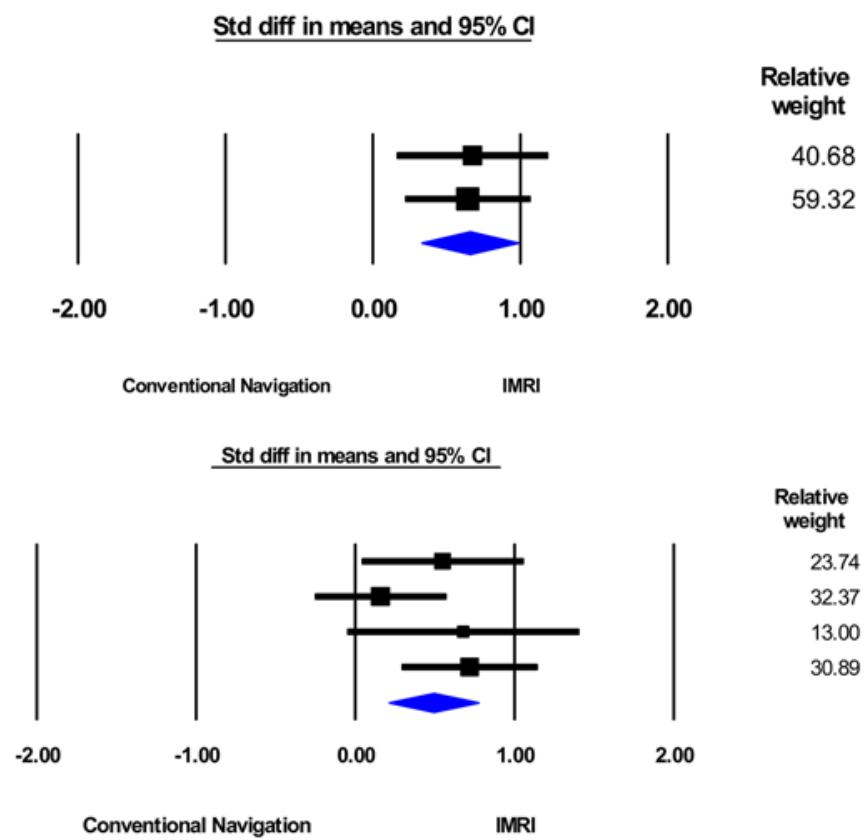

FIG. 2. Forest plots depicting primary and secondary outcomes in a classic meta-analysis comparison of IMRI to conventional navigation (random-effects models). A: Odds ratio for achieving GTR. B: Standard difference (Std diff) in means for progressionfree survival. C: Standard difference in means for overall survival.

the relative impact of retrospective versus prospective studies on observed outcomes. Among the IMRI studies, the prospective studies were sufficient to demonstrate an increased rate of GTR associated with IMRI (OR 3.549, 95\% CI 1.680-7.501, $\mathrm{p}=0.001$ ), and retrospective studies contributed an artificially elevated outcome, with nearly four times greater odds of achieving GTR and a wide confidence interval, implying severe interstudy heterogeneity (OR 7.319, 95\% CI 2.177-24.608, p = 0.001; Fig. 6A). Among the 5-ALA studies, the analysis of GTR in the prospective studies alone showed a nonsignificant relationship with increased GTR with 5-ALA (OR 2.019, 95\% CI $0.758-5.377, p=0.160 ;$ Fig. 6B). Retrospective studies only contributed a 1.5 times greater contribution to the odds ratio outcome (OR 3.079, 95\% CI 2.159-4.391, p < 0.001), implying a lower contribution of bias from the retrospective literature among the 5-ALA studies versus the IMRI studies.

\section{Discussion}

In gliomas, EOR is a well-defined determinant of overall patient survival. ${ }^{49}$ Since the late 1990 s, both IMRI and 5-ALA have seen growing interest in the neurosurgical community for their potential to provide real-time feedback on tumor localization. ${ }^{13,23,36}$ Our meta-analysis confirms that both IMRI and 5-ALA individually improve the rate of GTR over conventional stereotactic navigation and, accordingly, prolong both progression-free and overall survival. Our network meta-analysis revealed that between IMRI and 5-ALA, neither intervention was clearly superior in attaining GTR, with a slight trend favoring IMRI. However, if carefully considering the potential risk of bias from the contribution of retrospective studies, as well as the increased interstudy heterogeneity among IMRI studies, it is likely that the effect size of IMRI is artificially elevated and that the two modalities are truly equally ef- 


\begin{tabular}{lllrr} 
Study name & \multicolumn{4}{c}{ Statistics for each study } \\
\cline { 2 - 5 } & $\begin{array}{c}\text { Odds } \\
\text { ratio }\end{array}$ & $\begin{array}{c}\text { Lower } \\
\text { limit }\end{array}$ & $\begin{array}{c}\text { Upper } \\
\text { limit }\end{array}$ & p-Value \\
Bruch 2011 & 2.781 & 1.414 & 5.469 & 0.003 \\
Diez Valle 2014 & 2.501 & 1.499 & 4.174 & 0.000 \\
Kim 2014 & 5.412 & 1.998 & 14.661 & 0.001 \\
Nickel 2018 & 1.018 & 0.302 & 3.436 & 0.977 \\
Roder 2014 & 4.981 & 1.766 & 14.045 & 0.002 \\
Stummer 2011 & 2.908 & 1.883 & 4.491 & 0.000 \\
& 2.866 & 2.127 & 3.863 & 0.000
\end{tabular}

A

\begin{tabular}{lrllr} 
Study name & \multicolumn{4}{c}{ Statistics for each study } \\
& $\begin{array}{c}\text { Std diff } \\
\text { in means }\end{array}$ & $\begin{array}{c}\text { Lower } \\
\text { limit }\end{array}$ & $\begin{array}{c}\text { Upper } \\
\text { limit }\end{array}$ & p-Value \\
Kim 2014 & 0.765 & 0.311 & 1.219 & 0.001 \\
Stummer 2011 & 0.319 & 0.108 & 0.530 & 0.003 \\
& 0.495 & 0.068 & 0.922 & 0.023
\end{tabular}

\section{B}

\begin{tabular}{lrccr} 
Study name & \multicolumn{4}{c}{ Statistics for each study } \\
& $\begin{array}{c}\text { Std diff } \\
\text { in means }\end{array}$ & $\begin{array}{c}\text { Lower } \\
\text { limit }\end{array}$ & $\begin{array}{c}\text { Upper } \\
\text { limit }\end{array}$ & p-Value \\
Kim 2014 & 0.456 & 0.012 & 0.899 & 0.044 \\
Stummer 2011 & 0.177 & -0.034 & 0.387 & 0.100 \\
& 0.245 & 0.010 & 0.480 & 0.041
\end{tabular}

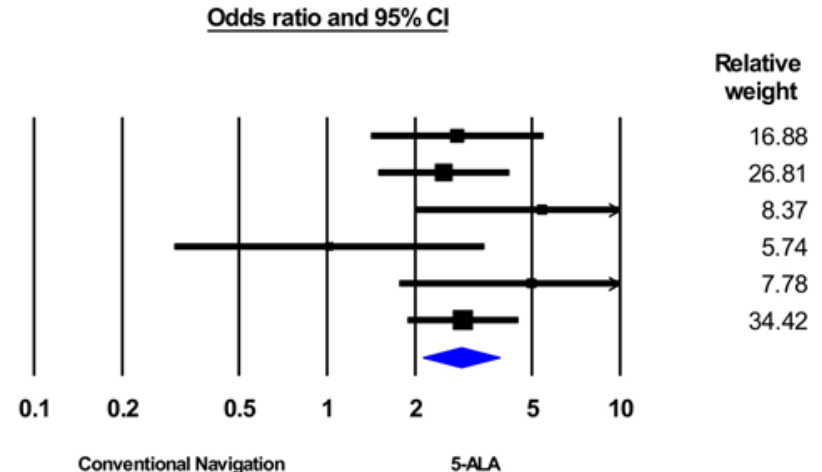

Std diff in means and $95 \% \mathrm{Cl}$

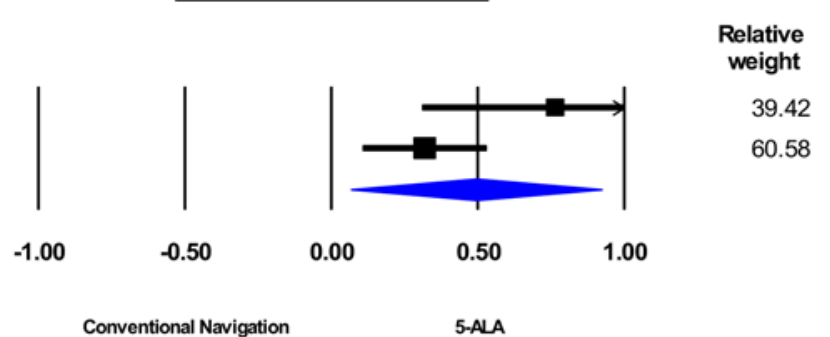

Std diff in means and $95 \% \mathrm{Cl}$
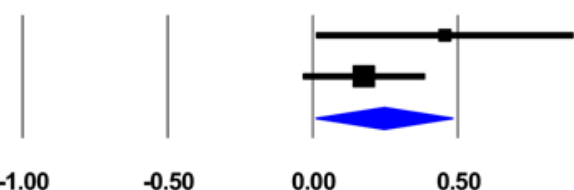

Relative weight

24.44

75.56

$-1.00$

$-0.50$

0.00

0.50

1.00

C

Conventional Navigation

5-ALA

FIG. 3. Forest plots depicting primary and secondary outcomes in a classic meta-analysis comparison of 5-ALA to conventional navigation (random-effects models). A: Odds ratio for achieving GTR. B: Standard difference (Std diff) in means for progressionfree survival. C: Standard difference in means for overall survival.

fective. It remains unclear whether these two techniques are complementary and if the use of both is additive. In our exhaustive literature search, we found only one article describing the combination of IMRI and 5-ALA that fit our inclusion criteria, ${ }^{40}$ and including a "combination" arm into our network meta-analysis with data from this single study would introduce significant bias. All articles from our screening that describe the use of a combination of IMRI and 5-ALA for HGG resection (and reasons for exclusion) are reviewed in Table $3.10-12,20,21,24,26,40,44,51,67,71$ While the outcomes of these studies were heterogeneous, some common themes emerged: 1) 5-ALA was more sensitive than IMRI for identifying tumor at the infiltrating edge, and 2) a high GTR rate and/or EOR were consistently achievable across series using the combination approach. These data and the potential for synergy between IMRI and 5-ALA have significant implications for patient care decisions, program development, and healthcare spending in neurosurgery.
The existing literature (and our study) clearly shows that IMRI increases the rate of GTR over conventional neuronavigation..$^{8,39,40,45,53,55,70,74}$ As with any technology, IMRI is imperfect and has several important limitations: IMRI is an "off-line" method that requires the surgeon to pause the procedure for image acquisition and often involves moving the patient to a separate room, adding surgical time and possibly increasing infection rates.,21 Additionally, the cost of installing an IMRI suite can be prohibitive. ${ }^{2}$ Image interpretation can be ambiguous as contrast can lead to false-positive interpretations, and blood and CSF artifact in the cavity can obfuscate images..$^{27,33}$ In our review, the majority of IMRI studies used high-field $(\geq 1.5 \mathrm{~T})$ magnets, which provide enhanced image quality. However, multiple series have described the comparable efficacy of low- and high-field IMRI in detecting residual tumor tissue, ${ }^{54,56} \mathrm{es}-$ pecially when adjusting the gadolinium dose ${ }^{34}$ Low-field magnets may provide a more cost-effective option. ${ }^{25}$

Likewise, 5-ALA (Gliolan) has become a popular in- 


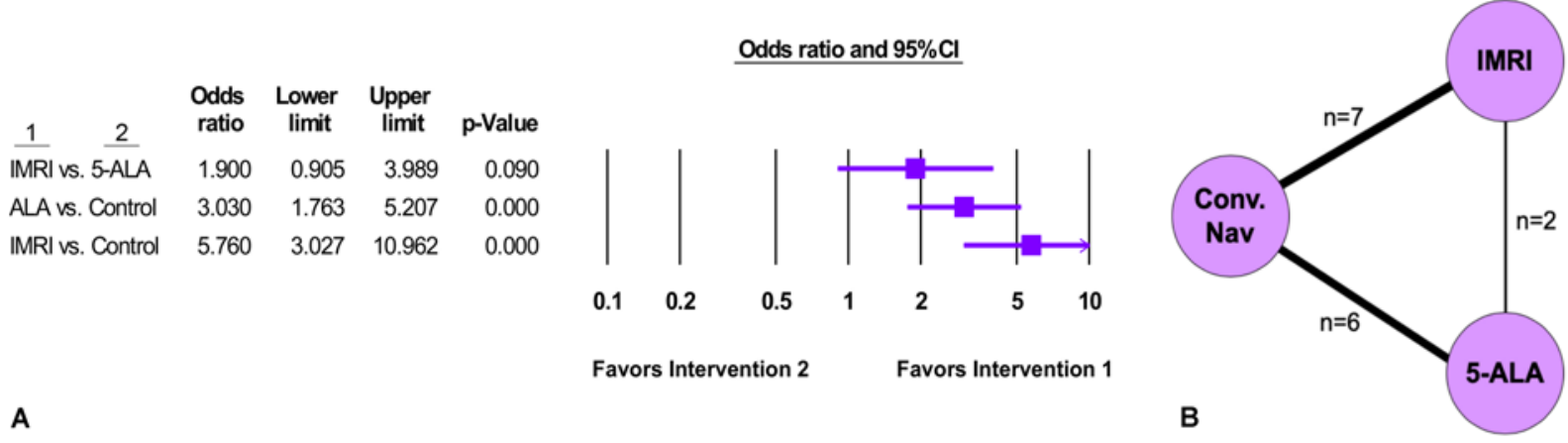

FIG. 4. A: Forest plot depicting Markov chain Monte Carlo Bayesian network analysis for direct comparison of IMRI and 5-ALA across all included studies using a random-effects model. Comparisons of 5-ALA and IMRI to conventional navigation are also shown. B: Comparison network indicating number of studies with direct comparison available.

traoperative imaging tool with widespread use in Europe and recent FDA approval in the US. ${ }^{58}$ First described as an adjunct for HGG visualization by Stummer et al. in 1998, 5-ALA is a natural intermediate in the heme synthesis pathway that is converted intratumorally to fluorescent protoporphyrin IX (PpIX), which is visible intraoperatively under blue light (wavelength range $375-440 \mathrm{~nm}$ ). ${ }^{61}$ The sensitivity and specificity of 5-ALA for HGG tissue have been as high as $95 \%$ and $100 \%$, respectively. ${ }^{24,71}$ Several studies, ours included, have confirmed the utility of 5-ALA for increasing EOR over conventional stereotactic navigation. 6,17,32,45,60,62 Moreover, oral 5-ALA has an excellent side effect profile; the most common side effect reported is hypotension, mostly seen in patients already on antihypertensives or in those with chronic hypotension. ${ }^{9}$ Additionally, despite a less than $1 \%$ reaction rate, patients are put on photosensitivity precautions, including complete skin and eye coverage, for up to 48 hours after ingestion of 5-ALA..$^{60}$ Transient increases in serum transaminases, as well as gastrointestinal complaints including nausea, vomiting, and diarrhea, have been reported after surgery with 5-ALA but are likely better explained by the effects of anesthetic agents (such as propofol and volatile gases). ${ }^{64}$

\section{Economic Impact}

The cost of an IMRI unit is exorbitant, ranging between $\$ 3$ and \$7 million-not including the cost of remodeling the surgical suite, the IMRI-compatible instruments, and the extended surgical time. ${ }^{1}$ All of the existing IMRI suites in the UK, and several in the US, were funded by large charitable donations. ${ }^{14,65}$ On the other hand, the fluorescence modules for surgical microscopes only cost between $\$ 34,000$ and $\$ 51,000$ in Europe..$^{57}$ 5-ALA itself also entails a relatively low additional cost of $\$ 1100$ per patient. ${ }^{57}$ In an era of rising healthcare costs and value-based healthcare delivery, comparing the relative costs, benefits, and overall accessibility of IMRI and 5-ALA has become a critical responsibility of the neurosurgical and neuro-oncological community.

Economic outcomes in healthcare are measured in quality-adjusted life years (QALYs), and in HGG surgery, the threshold for cost-effectiveness is estimated at an addition- al \$50,000 per QALY..$^{18}$ Only 2 studies to date have reported the increase in cost per QALY associated with 5-ALA (around \$10,000 per QALY). ${ }^{19,57}$ One meta-analysis determined that 5-ALA costs about half of what IMRI does $\left(\$ 16,218\right.$ vs $\$ 32,954$ per QALY)..$^{18}$ Another consideration is that IMRI increases surgical time given the increased complexity of the operative setup and the time required for patient transfer to the IMRI suite during surgery. Among our included studies, surgical time was either not reported or reported too heterogeneously for quantitative synthesis, but across the literature, IMRI was associated with an average increase of 33-60 minutes in surgical time. ${ }^{18}$ However, some of the cost of IMRI is likely ameliorated by its utility across multiple pathologies. IMRI has been shown in several series to improve the EOR of low-grade gliomas (LGGs) by using T2/FLAIR sequences. ${ }^{42,46}$ While useful for prognosticating LGG when there are pockets of fluorescence indicating malignant transformation, ${ }^{69}$ 5-ALA is typically only visible intraoperatively in $15 \%-20 \%$ of LGGs..$^{30}$ IMRI is also highly beneficial for the resection of other contrast-enhancing tumors, particularly skull base lesions such as pituitary adenomas ${ }^{52}$ and meningiomas, ${ }^{7}$ as well as in other T2/FLAIR-hyperintense pathologies such as cortical dysplasia. ${ }^{48}$ IMRI has also been shown to improve localization accuracy in stereotactic procedures such as deep brain stimulation ${ }^{15}$ and laser interstitial thermal therapy. ${ }^{43}$ While further research is warranted to better determine cost-effectiveness (especially in the US), our data demonstrating equal clinical efficacy combined with previously reported economic outcomes favor 5-ALA over IMRI specifically for HGG resection in a crude cost-benefit analysis, with the caveat that IMRI currently has more applications in other pathologies.

The call for a better quality of evidence and for enhanced cost-benefit analysis of IMRI and 5-ALA has prompted a small number of clinical trials. The first headto-head parallel assignment study evaluating IMRI versus 5-ALA-guided HGG resection is ongoing in Germany and will additionally assess outcomes based on molecular subgroups (NCT02379572). Another randomized study evaluating the added value of IMRI over 5-ALA alone is being planned in Germany as well (NCT01798771). Ad- 
Golub et al.

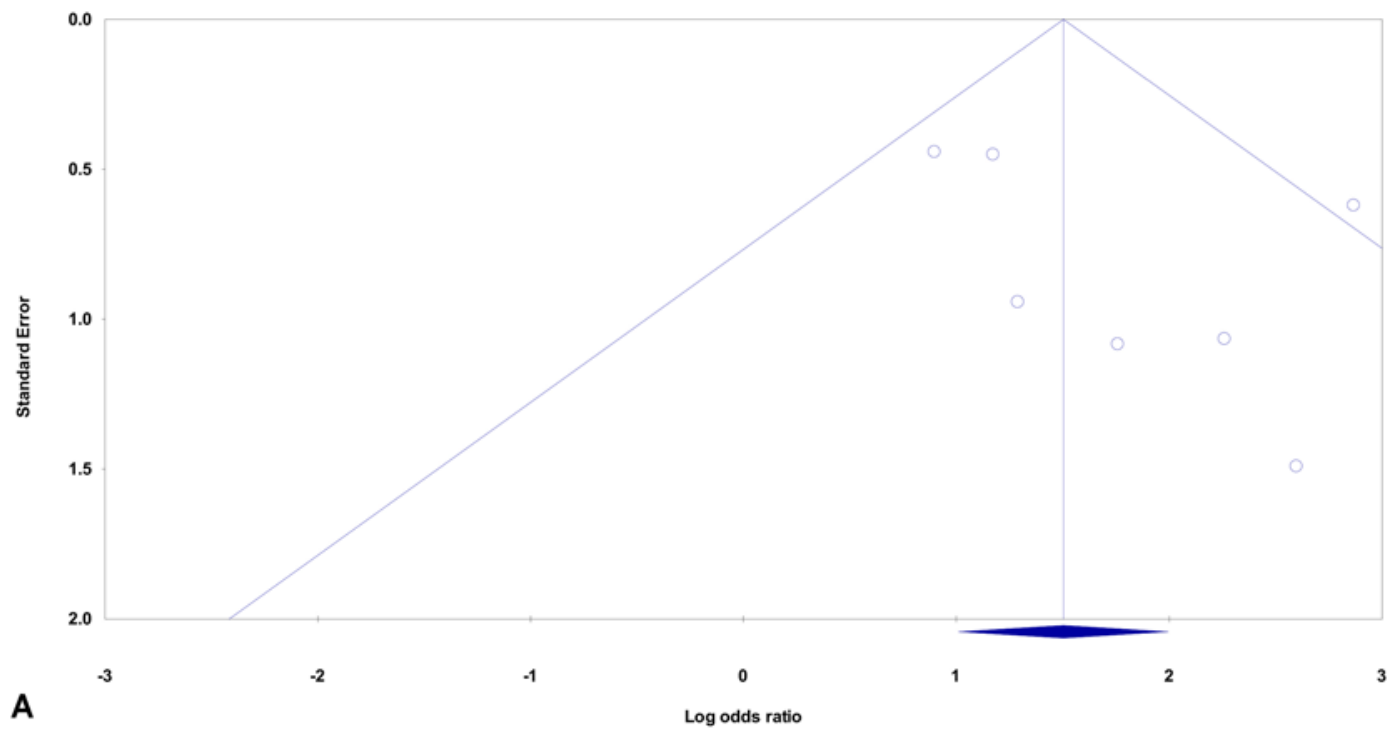

A

Log odds ratio
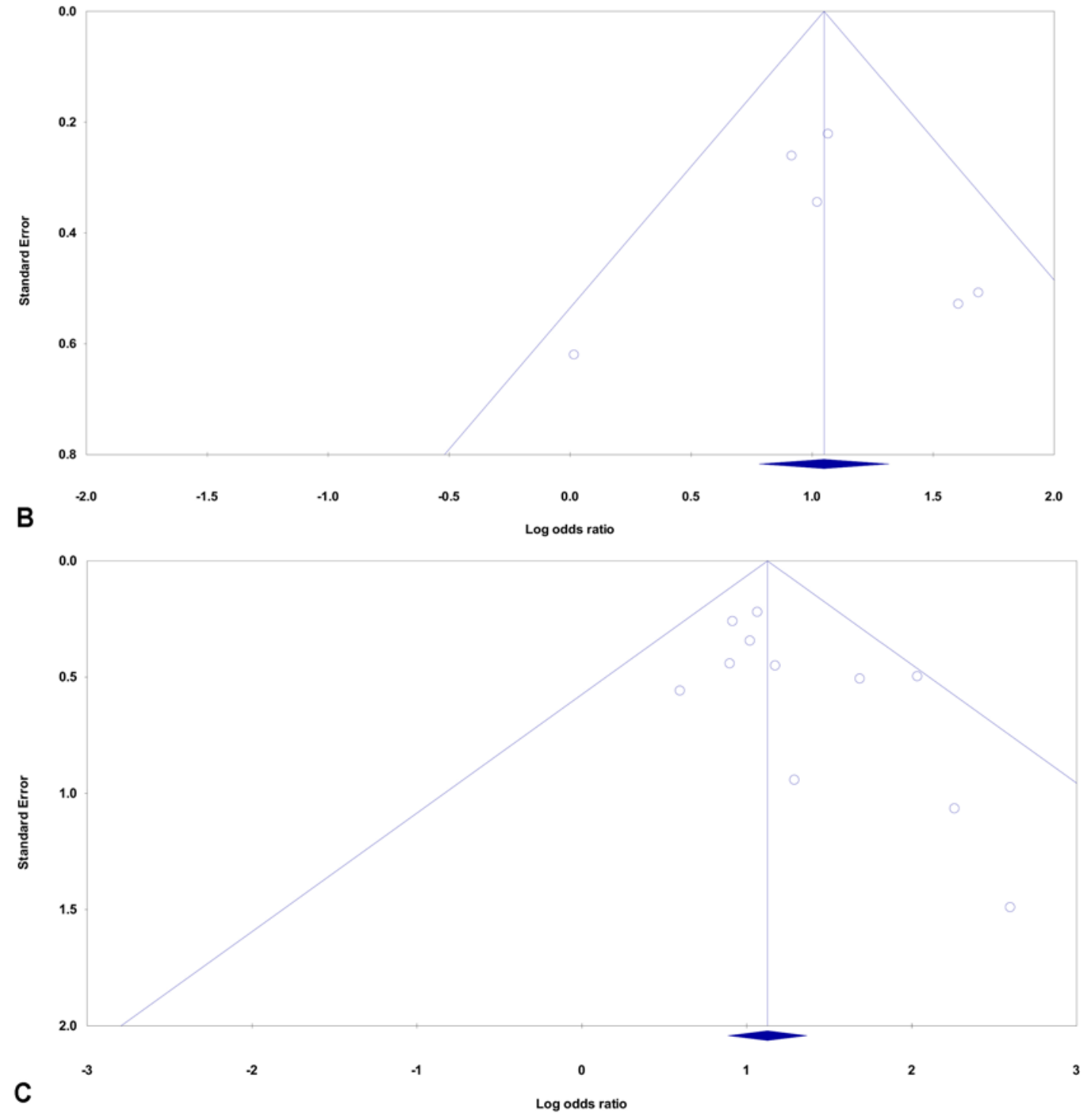

FIG. 5. Funnel plots of standard error versus log odds ratio for the primary outcome (GTR) for IMRI versus conventional navigation (classic meta-analysis, A), 5-ALA versus conventional navigation (classic meta-analysis, B), and IMRI and 5-ALA versus conventional navigation (network meta-analysis, C).

492 J Neurosurg Volume $134 \cdot$ February 2021

Unauthenticated | Downloaded ๑4/26/23 ०3:०9 AM UTC 


\begin{tabular}{|c|c|c|c|c|c|}
\hline \multirow{2}{*}{$\begin{array}{l}\text { Group by } \\
\text { Study Type }\end{array}$} & \multirow[t]{2}{*}{$\underline{\text { Study name }}$} & \multicolumn{4}{|c|}{ Statistics for each study } \\
\hline & & $\begin{array}{l}\text { Odds } \\
\text { ratio }\end{array}$ & $\begin{array}{l}\text { Lower } \\
\text { limit }\end{array}$ & $\begin{array}{c}\text { Upper } \\
\text { limit }\end{array}$ & p-Value \\
\hline Prospective/RCT & Nickel 2018 & 5.818 & 0.694 & 48.743 & 0.104 \\
\hline Prospective/RCT & Wu 2014 & 3.636 & 0.572 & 23.126 & 0.171 \\
\hline Prospective/RCT & Zhang 2015 & 3.239 & 1.335 & 7.859 & 0.009 \\
\hline Prospective/RCT & & 3.549 & 1.680 & 7.501 & 0.001 \\
\hline Retrospective & Chen 2017 & 9.600 & 1.186 & 77.729 & 0.034 \\
\hline Retrospective & Napolitano 201 & 42.460 & 1.032 & 5.866 & 0.042 \\
\hline Retrospective & Roder 2014 & 17.619 & 5.209 & 59.594 & 0.000 \\
\hline Retrospective & Senft 2010 & 13.462 & 0.723 & 250.736 & 0.081 \\
\hline Retrospective & & 7.319 & 2.177 & 24.608 & 0.001 \\
\hline Overall & & 4.333 & 2.292 & 8.192 & 0.000 \\
\hline
\end{tabular}

A

\begin{tabular}{llllllr} 
Group by & Study name & & \multicolumn{4}{c}{ Statistics for each study } \\
\cline { 5 - 7 } & & & $\begin{array}{c}\text { Odds } \\
\text { Study Type }\end{array}$ & $\begin{array}{c}\text { Lower } \\
\text { limit }\end{array}$ & $\begin{array}{c}\text { Upper } \\
\text { limit }\end{array}$ & p-Value \\
Prospective/RCT & Nickel 2018 & 1.018 & 0.302 & 3.436 & 0.977 \\
Prospective/RCT & Stummer 2011 & 2.908 & 1.883 & 4.491 & 0.000 \\
Prospective/RCT & & 2.019 & 0.758 & 5.377 & 0.160 \\
Retrospective & Bruch 2011 & 2.781 & 1.414 & 5.469 & 0.003 \\
Retrospective & Diez Valle 2014 & 2.501 & 1.499 & 4.174 & 0.000 \\
Retrospective & Kim 2014 & 5.412 & 1.998 & 14.661 & 0.001 \\
Retrospective & Roder 2014 & 4.981 & 1.766 & 14.045 & 0.002 \\
Retrospective & & 3.079 & 2.159 & 4.391 & 0.000 \\
Overall & & 2.932 & 2.100 & 4.094 & 0.000
\end{tabular}

B

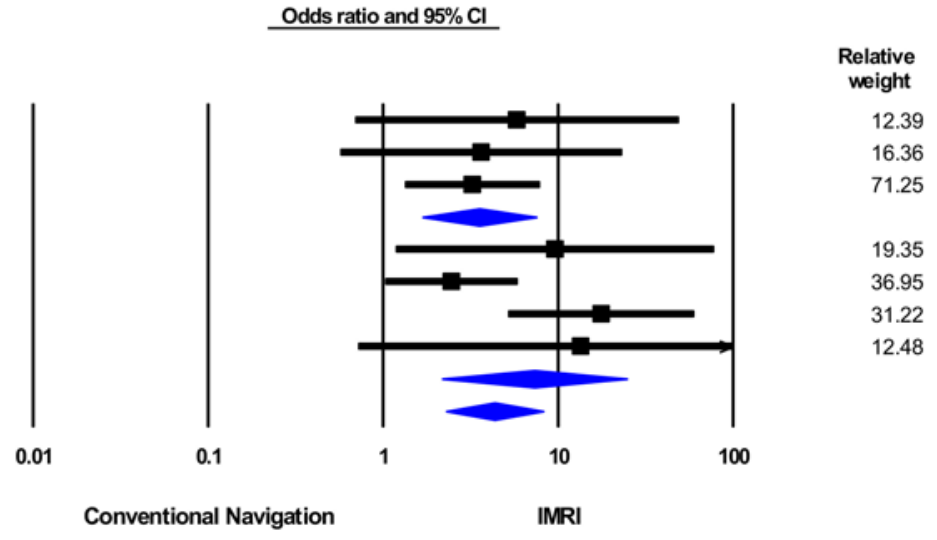

Odds ratio and $95 \% \mathrm{Cl}$

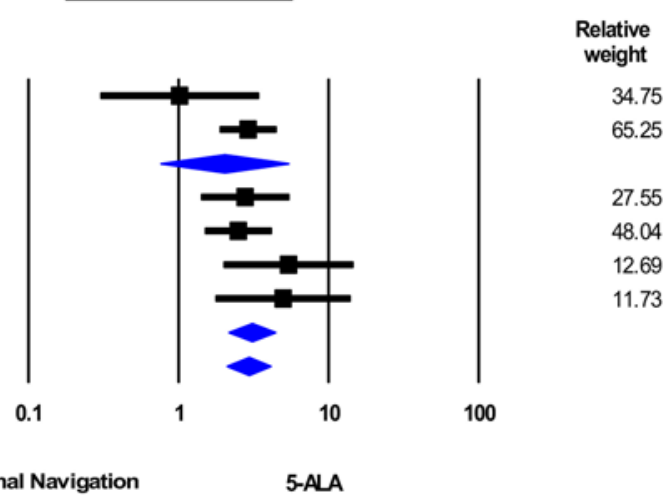

FIG. 6. Forest plots depicting the primary outcome, i.e., odds of GTR, by study type subgroup for IMRI versus conventional navigation (A) and 5-ALA versus conventional navigation (B; both comparisons are random-effects models).

ditionally, there are several ongoing studies evaluating an expanded role for 5-ALA in other pathologies such as LGG (NCT02473380, NCT01502280).

\section{Study Limitations}

Preliminary literature searches revealed that the most common definition of GTR in HGG was 100\% resection of the contrast-enhancing lesion. At the expense of excluding a handful of articles with altered definitions (i.e., $95 \%$ or $98 \%$ resection of contrast-enhancing tumor), the primary endpoint of $100 \%$ resection was chosen to optimize data uniformity and study yield. We were additionally inclusive of studies using various additional navigational tools such as neuromonitoring or ultrasound given the current lack of evidence for any significant influence on GTR rates with these tools as compared to existing evidence and clinical interest related to IMRI and 5-ALA. Future studies on neuronavigational adjuncts and meta-analyses would benefit from outcome data based on a more standardized GTR definition.

It must be noted that using a primary endpoint based on postoperative MRI likely biases our data toward favoring IMRI over 5-ALA and thus may not be the ideal assessment of the tumor margin. Postmortem study of HGG specimens has demonstrated that resection of the contrastenhancing lesion alone is insufficient-by a margin of at least $1 \mathrm{~cm}$-to ensure removal of prognostically critical infiltrating cells. ${ }^{72}$ Radiological studies comparing more highly sensitive and specific ${ }^{18} \mathrm{~F}$-FET PET imaging to MRI have also corroborated the shortfalls of contrast MRI for visualization of the HGG margin..$^{22}$ 5-ALA, on the other hand, may be a superior approximator of the true tumor margin based on both pathology and ${ }^{18} \mathrm{~F}-\mathrm{FET}$ PET imaging. ${ }^{10,47}$ Therefore, we must view the trend favoring IMRI for GTR in our analysis more critically with the understanding of potential underlying bias stemming from the outcome measure of GTR on postoperative MRI.

Another limitation of this analysis was the need to include observational studies and the limited quality of evidence of the included RCTs given issues with blinding. We were also unable to quantitatively assess outcomes by tumor location (eloquent vs noneloquent). While several studies noted the distribution of eloquent and noneloquent tumors within study arms, none commented on differences in the achieved EOR within these subgroups (with the exception of 2 studies conducted entirely in eloquent tumors). ${ }^{8,74}$ Likewise, heterogeneity in reported neurological deficits did not permit meaningful quantitative synthesis. A descriptive synthesis of postoperative deficits was included in Tables 1 and 2; most studies did not find significant differences in postoperative deficits between interventions, and any differences found must be weighed against the confounding issue of unknown eloquence/localization of the lesion. The IMRI- and 5-ALA-specific 


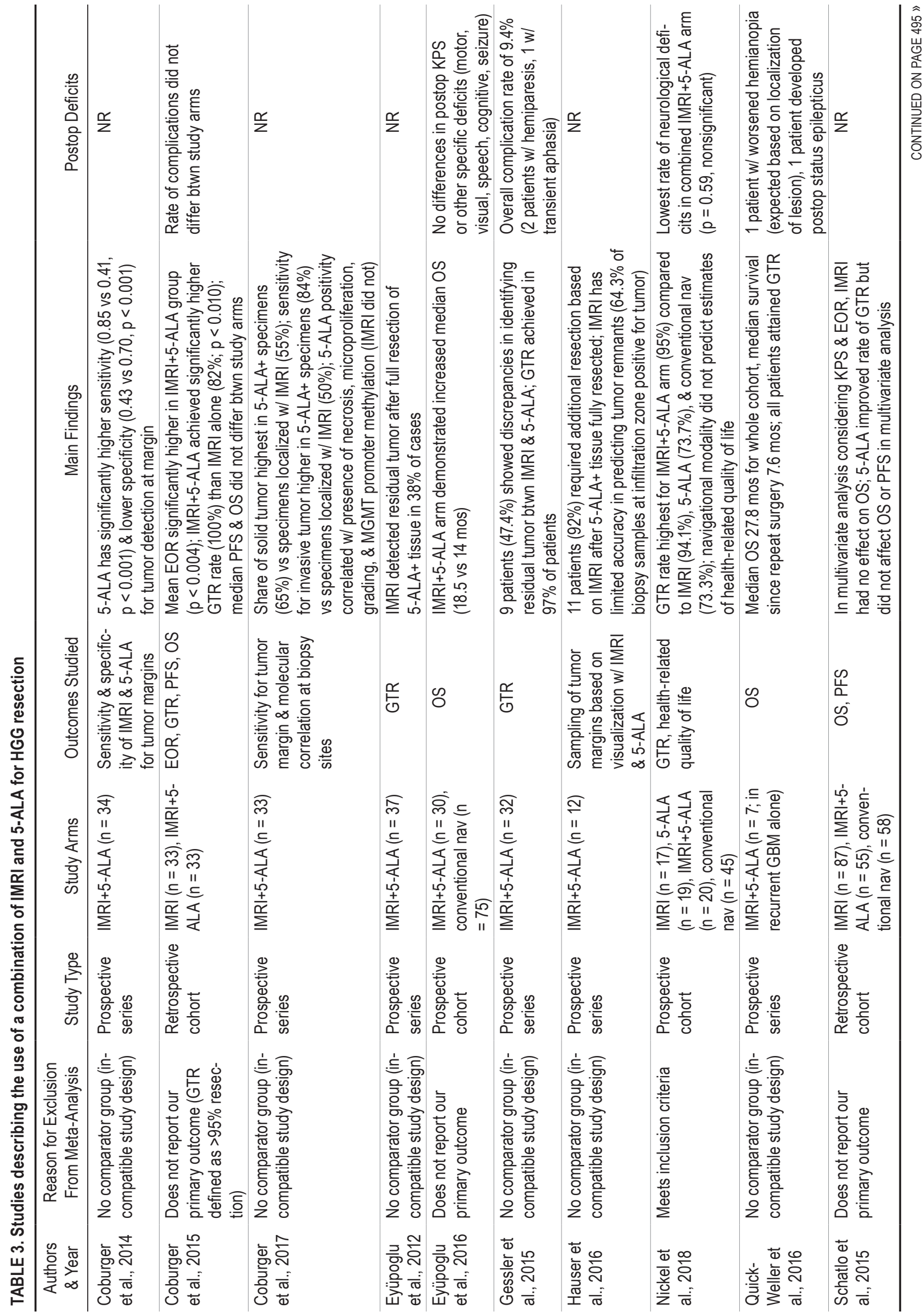


literature also spanned slightly different study periods (2004-2014 and 1999-2016, respectively), and both included studies that evaluated survival outcomes prior to the Stupp chemoradiation protocol published in 2005. ${ }^{63}$ The variations in study period may also influence the use of additional navigational adjuncts (neurophysiological monitoring, DTI, ultrasound, etc.), with greater use of these tools in recent years. A sensitivity analysis removing studies that included surgeries performed prior to $2005^{55,62}$ was, nevertheless, found to be consistent with our original network meta-analysis findings for GTR (Supplemental Fig. S2). Lastly, only 2 of the 11 included studies gave GTR outcomes for both IMRI and 5-ALA, necessitating the use of Bayesian network meta-analysis methods to estimate their relative effectiveness. This analysis is inherently an indirect comparison and meant to be hypothesis generating; a randomized trial directly comparing the two methods is needed to definitively establish equipoise or the superiority of one method over the other.

\section{Conclusions}

IMRI and 5-ALA individually provide significant resection and survival benefit over conventional stereotactic navigation. When comparing IMRI and 5-ALA, neither intervention was found to be superior for achieving GTR. Additional literature review potentially supports a relatively greater benefit of 5-ALA in HGG surgery when considering histopathologically true tumor margins and cost burden; however, unlike 5-ALA, IMRI has demonstrated significant utility across multiple pathologies. While the limited availability of level I evidence and data heterogeneity limit the conclusiveness and generalizability of our analysis, it is clear that both adjuncts contribute meaningfully to HGG surgery, and attempts to incorporate at least one of these neuronavigational tools should be made across operating centers.

\section{Importance of the Study}

While HGG continues to have poor survival outcomes, surgical EOR has come to be known as a critical prognostic factor. Surgery using conventional stereotactic neuronavigation is limited by intraoperative brain shift and vague tumor margins. Intraoperative visualization adjuncts, such as IMRI and 5-ALA fluorescence, are becoming increasingly popular neuronavigational aids. While several prior studies have compared either IMRI or 5-ALA with stereotactic navigation, direct comparisons of surgical outcomes with IMRI versus 5-ALA remain limited. We performed an exhaustive systematic review and meta-analysis of the comparative effectiveness of IMRI and 5-ALA for achieving GTR in HGG surgery. We secondarily analyzed associated survival outcomes. Our findings indicate that between IMRI and 5-ALA, neither surgical adjunct is superior, but both are better than conventional image guidance alone. These results have significant implications for economically prudently incorporating these novel neuronavigational aids into routine neurosurgical care.

\section{Appendix}


Central, Web of Science).

1. "magnetic resonance imaging, interventional" [MeSH]

2. "intraoperative MRI" $[\mathrm{tw}]$

3. "intraoperative magnetic resonance imaging" $[\mathrm{tw}]$

4. "intraoperative MR" $[\mathrm{tw}]$

5. "IMRI" [tw]

6. 1 OR 2 OR 3 OR 4 OR 5

7. "5-ALA" [tw]

8. "aminolevulinic" $[\mathrm{tw}]$

9. "5-aminolevulinic" [tw]

10. 7 OR 8 OR 9

11. "neuronavigation" $[\mathrm{MeSH}]$

12. "neuronavigation" [tw]

13. "stereotactic" $[\mathrm{tw}]$

14. "brain lab" [tw]

15. "brainlab" [tw]

16. "MRI guidance" $[\mathrm{tw}]$

17. "MRI guided"'[tw]

18. "magnetic resonance imaging guided" $[\mathrm{tw}]$

19. "magnetic resonance imaging guidance" $[\mathrm{tw}]$

20. "image guidance" $[\mathrm{tw}]$

21. "image guided" $[\mathrm{tw}]$

22. 11 OR 12 OR 13 OR 14 OR 15 OR 16 OR 17 OR 18 OR 19

OR 20 OR 21

23. 6 OR 10 OR 22

24. "glioma" $[\mathrm{MeSH}]$

25. "astrocytoma" $[\mathrm{MeSH}]$

26. "oligodendroglioma"[MeSH]

27. "glioblastoma" $[\mathrm{MeSH}]$

28. "glioma" $[\mathrm{tw}]$

29. "astrocytoma" $[\mathrm{tw}]$

30. "oligodendroglioma" $[\mathrm{tw}]$

31. "glioblastoma" $[\mathrm{tw}]$

32. "gbm" $[\mathrm{tw}]$

33. "gliomas" $[\mathrm{tw}]$

34. "astrocytomas" $[\mathrm{tw}]$

35. "oligodendrogliomas" $[\mathrm{tw}]$

36. "glioblastomas" $[\mathrm{tw}]$

37. "gbms" $[\mathrm{tw}]$

38. 24 OR 25 OR 26 OR 27 OR 28 OR 29 OR 30 OR 31 OR

32 OR 33 OR 34 OR 35 OR 36 OR 37

39. 23 AND 38

\section{References}

1. Advisory Board: WSJ: Intraoperative imaging gaining traction. Wall Street Journal Daily Briefing. February 19, 2015 (https://www.advisory.com/daily-briefing/2015/02/19/intraoperative\%20imaging) [Accessed January 9, 2020]

2. Barbosa BJ, Mariano ED, Batista CM, Marie SK, Teixeira MJ, Pereira CU, et al: Intraoperative assistive technologies and extent of resection in glioma surgery: a systematic review of prospective controlled studies. Neurosurg Rev 38:217227, 2015

3. Borenstein M, Hedges LV, Higgins JP, Rothstein HR: A basic introduction to fixed-effect and random-effects models for meta-analysis. Res Synth Methods 1:97-111, 2010

4. Brat DJ, Verhaak RG, Aldape KD, Yung WK, Salama SR, Cooper LA, et al: Comprehensive, integrative genomic analysis of diffuse lower-grade gliomas. N Engl J Med 372:24812498,2015

5. Brown S, Hutton B, Clifford T, Coyle D, Grima D, Wells G, et al: A Microsoft-Excel-based tool for running and critically appraising network meta-analyses - an overview and application of NetMetaXL. Syst Rev 3:110, 2014

6. Bruch JD, Ho J, Watts C, Price SJ: A single centre case control study of the efficacy and safety of 5-aminolevulinic acid guided resections of grade IV (WHO) glioblastomas. Neuro Oncol 13 (Suppl 2):ii1-ii14, 2011 (Abstract)
7. Chakraborty S, Zavarella S, Salas S, Schulder M: Intraoperative MRI for resection of intracranial meningiomas. J Exp Ther Oncol 12:157-162, 2017

8. Chen LF, Yang Y, Ma XD, Yu XG, Gui QP, Xu BN, et al: Optimizing the extent of resection and minimizing the morbidity in insular high-grade glioma surgery by high-field intraoperative MRI guidance. Turk Neurosurg 27:696-706, 2017

9. Chung IW, Eljamel S: Risk factors for developing oral 5-aminolevulinic acid-induced side effects in patients undergoing fluorescence guided resection. Photodiagn Photodyn Ther 10:362-367, 2013

10. Coburger J, Engelke J, Scheuerle A, Thal DR, Hlavac M, Wirtz CR, et al: Tumor detection with 5-aminolevulinic acid fluorescence and Gd-DTPA-enhanced intraoperative MRI at the border of contrast-enhancing lesions: a prospective study based on histopathological assessment. Neurosurg Focus 36(2):E3, 2014

11. Coburger J, Hagel V, Wirtz CR, König R: Surgery for glioblastoma: impact of the combined use of 5-aminolevulinic acid and intraoperative MRI on extent of resection and survival. PLoS One 10:e0131872, 2015

12. Coburger J, Scheuerle A, Pala A, Thal D, Wirtz CR, König R: Histopathological insights on imaging results of intraoperative magnetic resonance imaging, 5-aminolevulinic acid, and intraoperative ultrasound in glioblastoma surgery. Neurosurgery 81:165-174, 2017

13. Coburger J, Wirtz CR: Fluorescence guided surgery by 5-ALA and intraoperative MRI in high grade glioma: a systematic review. J Neurooncol 141:533-546, 2019

14. Cook Children's: Promise: The Winter Issue 2016 [Press Release]. Fort Worth, TX: Cook Children's Health Care System, 2016, p 29 (https://cookchildrens.org/SiteCollectionDocuments/giving/promise-magazine/Promise-Holiday2016. pdf) [Accessed January 9, 2020]

15. Cui Z, Pan L, Song H, Xu X, Xu B, Yu X, et al: Intraoperative MRI for optimizing electrode placement for deep brain stimulation of the subthalamic nucleus in Parkinson disease. J Neurosurg 124:62-69, 2016

16. Dias S, Sutton AJ, Ades AE, Welton NJ: Evidence synthesis for decision making 2: a generalized linear modeling framework for pairwise and network meta-analysis of randomized controlled trials. Med Decis Making 33:607-617, 2013

17. Díez Valle R, Slof J, Galván J, Arza C, Romariz C, Vidal C: Observational, retrospective study of the effectiveness of 5 -aminolevulinic acid in malignant glioma surgery in Spain (The VISIONA study). Neurologia 29:131-138, 2014

18. Eljamel MS, Mahboob SO: The effectiveness and costeffectiveness of intraoperative imaging in high-grade glioma resection; a comparative review of intraoperative ALA, fluorescein, ultrasound and MRI. Photodiagn Photodyn Ther 16:35-43, 2016

19. Esteves S, Alves M, Castel-Branco M, Stummer W: A pilot cost-effectiveness analysis of treatments in newly diagnosed high-grade gliomas: the example of 5-aminolevulinic acid compared with white-light surgery. Neurosurgery 76:552562,2015

20. Eyüpoglu IY, Hore N, Merkel A, Buslei R, Buchfelder M, Savaskan N: Supra-complete surgery via dual intraoperative visualization approach (DiVA) prolongs patient survival in glioblastoma. Oncotarget 7:25755-25768, 2016

21. Eyüpoglu IY, Hore N, Savaskan NE, Grummich P, Roessler $\mathrm{K}$, Buchfelder M, et al: Improving the extent of malignant glioma resection by dual intraoperative visualization approach. PLoS One 7:e44885, 2012

22. Filss CP, Galldiks N, Stoffels G, Sabel M, Wittsack HJ, Turowski B, et al: Comparison of 18F-FET PET and perfusion-weighted MR imaging: a PET/MR imaging hybrid study in patients with brain tumors. J Nucl Med 55:540-545, 2014 
23. Gerard IJ, Kersten-Oertel M, Petrecca K, Sirhan D, Hall JA, Collins DL: Brain shift in neuronavigation of brain tumors: a review. Med Image Anal 35:403-420, 2017

24. Gessler F, Forster MT, Duetzmann S, Mittelbronn M, Hattingen E, Franz K, et al: Combination of intraoperative magnetic resonance imaging and intraoperative fluorescence to enhance the resection of contrast enhancing gliomas. Neurosurgery 77:16-22, 2015

25. Hadani M, Spiegelman R, Feldman Z, Berkenstadt H, Ram Z: Novel, compact, intraoperative magnetic resonance imaging-guided system for conventional neurosurgical operating rooms. Neurosurgery 48:799-809, 2001

26. Hauser SB, Kockro RA, Actor B, Sarnthein J, Bernays RL: Combining 5-aminolevulinic acid fluorescence and intraoperative magnetic resonance imaging in glioblastoma surgery: a histology-based evaluation. Neurosurgery 78:475-483, 2016

27. Henegar MM, Moran CJ, Silbergeld DL: Early postoperative magnetic resonance imaging following nonneoplastic cortical resection. J Neurosurg 84:174-179, 1996

28. Higgins JP, Altman DG, Gøtzsche PC, Jüni P, Moher D, Oxman AD, et al: The Cochrane Collaboration's tool for assessing risk of bias in randomised trials. BMJ 343:d5928, 2011

29. Higgins JP, Thompson SG, Deeks JJ, Altman DG: Measuring inconsistency in meta-analyses. BMJ 327:557-560, 2003

30. Jaber M, Ewelt C, Wölfer J, Brokinkel B, Thomas C, Hasselblatt $\mathrm{M}$, et al: Is visible aminolevulinic acid-induced fluorescence an independent biomarker for prognosis in histologically confirmed (World Health Organization 2016) low-grade gliomas? Neurosurgery 84:1214-1224, 2019

31. Jenkinson MD, Barone DG, Bryant A, Vale L, Bulbeck H, Lawrie TA, et al: Intraoperative imaging technology to maximise extent of resection for glioma. Cochrane Database Syst Rev 1:CD012788, 2018

32. Kim SK, Choi SH, Kim YH, Park CK: Impact of fluorescence-guided surgery on the improvement of clinical outcomes in glioblastoma patients. Neurooncol Pract 1:81-85, 2014

33. Knauth M, Aras N, Wirtz CR, Dörfler A, Engelhorn T, Sartor K: Surgically induced intracranial contrast enhancement: potential source of diagnostic error in intraoperative MR imaging. AJNR Am J Neuroradiol 20:1547-1553, 1999

34. Knauth M, Wirtz CR, Aras N, Sartor K: Low-field interventional MRI in neurosurgery: finding the right dose of contrast medium. Neuroradiology 43:254-258, 2001

35. Kubben PL, Scholtes F, Schijns OE, Ter Laak-Poort MP, Teernstra OP, Kessels AG, et al: Intraoperative magnetic resonance imaging versus standard neuronavigation for the neurosurgical treatment of glioblastoma: a randomized controlled trial. Surg Neurol Int 5:70, 2014

36. Kubben PL, ter Meulen KJ, Schijns OE, ter Laak-Poort MP, van Overbeeke JJ, van Santbrink H: Intraoperative MRIguided resection of glioblastoma multiforme: a systematic review. Lancet Oncol 12:1062-1070, 2011

37. McGirt MJ, Chaichana KL, Attenello FJ, Weingart JD, Than $\mathrm{K}$, Burger PC, et al: Extent of surgical resection is independently associated with survival in patients with hemispheric infiltrating low-grade gliomas. Neurosurgery 63:700-708, 2008

38. Moher D, Liberati A, Tetzlaff J, Altman DG: Preferred reporting items for systematic reviews and meta-analyses: the PRISMA statement. Int J Surg 8:336-341, 2010

39. Napolitano M, Vaz G, Lawson TM, Docquier MA, van Maanen A, Duprez T, et al: Glioblastoma surgery with and without intraoperative MRI at 3.0T. Neurochirurgie 60:143150,2014

40. Nickel K, Renovanz M, König J, Stöckelmaier L, Hickmann AK, Nadji-Ohl M, et al: The patients' view: impact of the extent of resection, intraoperative imaging, and awake sur- gery on health-related quality of life in high-grade glioma patients - results of a multicenter cross-sectional study. Neurosurg Rev 41:207-219, 2018

41. Ostrom QT, Gittleman H, Liao P, Vecchione-Koval T, Wolinsky Y, Kruchko C, et al: CBTRUS Statistical Report: primary brain and other central nervous system tumors diagnosed in the United States in 2010-2014. Neuro Oncol 19 (suppl_5):v1-v88, 2017

42. Pamir MN, Ozduman K, Dinçer A, Yildiz E, Peker S, Ozek MM: First intraoperative, shared-resource, ultrahigh-field 3-Tesla magnetic resonance imaging system and its application in low-grade glioma resection. J Neurosurg 112:57-69, 2010

43. Pruitt R, Gamble A, Black K, Schulder M, Mehta AD: Complication avoidance in laser interstitial thermal therapy: lessons learned. J Neurosurg 126:1238-1245, 2017

44. Quick-Weller J, Lescher S, Forster MT, Konczalla J, Seifert $\mathrm{V}$, Senft C: Combination of 5-ALA and iMRI in re-resection of recurrent glioblastoma. Br J Neurosurg 30:313-317, 2016

45. Roder C, Bisdas S, Ebner FH, Honegger J, Naegele T, Ernemann U, et al: Maximizing the extent of resection and survival benefit of patients in glioblastoma surgery: high-field iMRI versus conventional and 5-ALA-assisted surgery. Eur J Surg Oncol 40:297-304, 2014

46. Roder C, Breitkopf M, Ms, Bisdas S, Freitas RdaS, Dimostheni A, et al: Beneficial impact of high-field intraoperative magnetic resonance imaging on the efficacy of pediatric lowgrade glioma surgery. Neurosurg Focus 40(3):E13, 2016

47. Roessler K, Becherer A, Donat M, Cejna M, Zachenhofer I: Intraoperative tissue fluorescence using 5-aminolevolinic acid (5-ALA) is more sensitive than contrast MRI or amino acid positron emission tomography $\left({ }^{18} \mathrm{~F}-\mathrm{FET}\right.$ PET) in glioblastoma surgery. Neurol Res 34:314-317, 2012

48. Sacino MF, Ho CY, Murnick J, Keating RF, Gaillard WD, Oluigbo CO: The role of intraoperative MRI in resective epilepsy surgery for peri-eloquent cortex cortical dysplasias and heterotopias in pediatric patients. Neurosurg Focus 40(3):E16, 2016

49. Sanai N, Polley MY, McDermott MW, Parsa AT, Berger MS: An extent of resection threshold for newly diagnosed glioblastomas. J Neurosurg 115:3-8, 2011

50. Schardt C, Adams MB, Owens T, Keitz S, Fontelo P: Utilization of the PICO framework to improve searching PubMed for clinical questions. BMC Med Inform Decis Mak 7:16, 2007

51. Schatlo B, Fandino J, Smoll NR, Wetzel O, Remonda L, Marbacher S, et al: Outcomes after combined use of intraoperative MRI and 5-aminolevulinic acid in high-grade glioma surgery. Neuro Oncol 17:1560-1567, 2015

52. Schwartz TH, Stieg PE, Anand VK: Endoscopic transsphenoidal pituitary surgery with intraoperative magnetic resonance imaging. Neurosurgery 58 (1 Suppl):ONS44-ONS51, 2006

53. Senft C, Bink A, Franz K, Vatter H, Gasser T, Seifert V: Intraoperative MRI guidance and extent of resection in glioma surgery: a randomised, controlled trial. Lancet Oncol 12:997-1003, 2011

54. Senft C, Forster MT, Bink A, Mittelbronn M, Franz K, Seifert V, et al: Optimizing the extent of resection in eloquently located gliomas by combining intraoperative MRI guidance with intraoperative neurophysiological monitoring. J Neurooncol 109:81-90, 2012

55. Senft C, Franz K, Blasel S, Oszvald A, Rathert J, Seifert V, et al: Influence of iMRI-guidance on the extent of resection and survival of patients with glioblastoma multiforme. Technol Cancer Res Treat 9:339-346, 2010

56. Senft C, Seifert V, Hermann E, Franz K, Gasser T: Usefulness of intraoperative ultra low-field magnetic resonance imaging in glioma surgery. Neurosurgery 63 (4 Suppl 2):257-267, 2008 
57. Slof J, Díez Valle R, Galván J: Cost-effectiveness of 5-aminolevulinic acid-induced fluorescence in malignant glioma surgery. Neurologia 30:163-168, 2015

58. Stepp H, Stummer W: 5-ALA in the management of malignant glioma. Lasers Surg Med 50:399-419, 2018

59. Sterne JA, Egger M: Funnel plots for detecting bias in metaanalysis: guidelines on choice of axis. J Clin Epidemiol 54:1046-1055, 2001

60. Stummer W, Pichlmeier U, Meinel T, Wiestler OD, Zanella F, Reulen HJ: Fluorescence-guided surgery with 5-aminolevulinic acid for resection of malignant glioma: a randomised controlled multicentre phase III trial. Lancet Oncol 7:392401, 2006

61. Stummer W, Stocker S, Wagner S, Stepp H, Fritsch C, Goetz $\mathrm{C}$, et al: Intraoperative detection of malignant gliomas by 5-aminolevulinic acid-induced porphyrin fluorescence. Neurosurgery 42:518-526, 1998

62. Stummer W, Tonn JC, Mehdorn HM, Nestler U, Franz $\mathrm{K}$, Goetz C, et al: Counterbalancing risks and gains from extended resections in malignant glioma surgery: a supplemental analysis from the randomized 5-aminolevulinic acid glioma resection study. J Neurosurg 114:613-623, 2011

63. Stupp R, Mason WP, van den Bent MJ, Weller M, Fisher $\mathrm{B}$, Taphoorn MJ, et al: Radiotherapy plus concomitant and adjuvant temozolomide for glioblastoma. $\mathbf{N}$ Engl J Med 352:987-996, 2005

64. Teixidor P, Arráez MA, Villalba G, Garcia R, Tardáguila M, González JJ, et al: Safety and efficacy of 5-aminolevulinic acid for high grade glioma in usual clinical practice: a prospective cohort study. PLoS One 11:e0149244, 2016

65. Thorne E: $\leq \mathbf{6 0 0 , 0 0 0}$ Donation for UK's First In-Theatre Intraoperative Brain Scanner [Press Release]. Nottingham, UK: University of Nottingham, 2014 (https://www. nottingham.ac.uk/news/pressreleases/2014/june/600,000donation-for-uks-first-in-theatre-intraoperative-brain-scanner. aspx) [Accessed January 9, 2020]

66. Tronnier VM, Wirtz CR, Knauth M, Lenz G, Pastyr O, Bonsanto MM, et al: Intraoperative diagnostic and interventional magnetic resonance imaging in neurosurgery. Neurosurgery 40:891-902, 1997

67. Tsugu A, Ishizaka H, Mizokami Y, Osada T, Baba T, Yoshiyama M, et al: Impact of the combination of 5-aminolevulinic acid-induced fluorescence with intraoperative magnetic resonance imaging-guided surgery for glioma. World Neurosurg 76:120-127, 2011

68. Wells GA SB, O'Connell D, Peterson J, Welch V, Losos M, Tugwell P: The Newcastle-Ottawa Scale (NOS) for Assessing the Quality of Nonrandomised Studies in Meta-Analyses. 2011 (http://www.ohri.ca/programs/clinical_epidemiology/oxford.asp) [Accessed January 9, 2020]

69. Widhalm G, Kiesel B, Woehrer A, Traub-Weidinger T, Preusser M, Marosi C, et al: 5-Aminolevulinic acid induced fluorescence is a powerful intraoperative marker for precise histopathological grading of gliomas with non-significant contrast-enhancement. PLoS One 8:e76988, 2013

70. Wu JS, Gong X, Song YY, Zhuang DX, Yao CJ, Qiu TM, et al: 3.0-T intraoperative magnetic resonance imaging-guided resection in cerebral glioma surgery: interim analysis of a prospective, randomized, triple-blind, parallel-controlled trial. Neurosurgery 61 (Suppl 1):145-154, 2014
71. Yamada S, Muragaki Y, Maruyama T, Komori T, Okada Y: Role of neurochemical navigation with 5-aminolevulinic acid during intraoperative MRI-guided resection of intracranial malignant gliomas. Clin Neurol Neurosurg 130:134-139, 2015

72. Yamahara T, Numa Y, Oishi T, Kawaguchi T, Seno T, Asai A, et al: Morphological and flow cytometric analysis of cell infiltration in glioblastoma: a comparison of autopsy brain and neuroimaging. Brain Tumor Pathol 27:81-87, 2010

73. Yang K, Nath S, Koziarz A, Badhiwala JH, Ghayur H, Sourour M, et al: Biopsy versus subtotal versus gross total resection in patients with low-grade glioma: a systematic review and meta-analysis. World Neurosurg 120:e762-e775, 2018

74. Zhang J, Chen X, Zhao Y, Wang F, Li F, Xu B: Impact of intraoperative magnetic resonance imaging and functional neuronavigation on surgical outcome in patients with gliomas involving language areas. Neurosurg Rev 38:319-330, 2015

75. Zhao S, Wu J, Wang C, Liu H, Dong X, Shi C, et al: Intraoperative fluorescence-guided resection of high-grade malignant gliomas using 5-aminolevulinic acid-induced porphyrins: a systematic review and meta-analysis of prospective studies. PLoS One 8:e63682, 2013

\section{Disclosures}

The authors report no conflict of interest concerning the materials or methods used in this study or the findings specified in this study.

\section{Author Contributions}

Conception and design: Golub, Nicholson, Schwartz. Acquisition of data: Golub, Hyde, Dogra. Analysis and interpretation of data: Golub, Nicholson, Kirkwood, Loftus, Schwartz. Drafting the article: Golub, Hyde, Dogra, Gohel. Critically revising the article: Golub, Hyde, Dogra, Nicholson, Kirkwood, Schwartz. Reviewed submitted version of manuscript: all authors. Approved the final version of the manuscript on behalf of all authors: Golub. Statistical analysis: Golub, Kirkwood, Loftus. Administrative/ technical/material support: Nicholson, Schwartz. Study supervision: Nicholson, Schwartz.

\section{Supplemental Information Online-Only Content}

Supplemental material is available with the online version of the article.

Supplemental Figures and Tables. https://thejns.org/doi/suppl/ 10.3171/2019.12.JNS191203.

\section{Correspondence}

Danielle Golub: New York University School of Medicine, New York, NY. danielle.golub@nyulangone.org. 